\title{
Preparing Datasets of Surface Roughness for Constructing Big Data from the Context of Smart Manufacturing and Cognitive Computing
}

\author{
Saman Fattahi ${ }^{1}$, Takuya Okamoto ${ }^{1}$ and Sharifu Ura ${ }^{2, *(D)}$ \\ 1 Graduate School of Engineering, Kitami Institute of Technology, 165 Koen-cho, Kitami 090-8507, Japan; \\ d2071308012@std.kitami-it.ac.jp (S.F.); m2052100060@std.kitami-it.ac.jp (T.O.) \\ 2 Division of Mechanical and Electrical Engineering, Kitami Institute of Technology, 165 Koen-cho, \\ Kitami 090-8507, Japan \\ * Correspondence: ullah@mail.kitami-it.ac.jp
}

\section{check for} updates

Citation: Fattahi, S.; Okamoto, T.; Ura, S. Preparing Datasets of Surface Roughness for Constructing Big Data from the Context of Smart

Manufacturing and Cognitive Computing. Big Data Cogn. Comput. 2021, 5, 58. https://doi.org/10.3390/ bdcc 5040058

Academic Editors:

Mohamed Eldefrawy and Mahmoud Eldefrawy

Received: 21 September 2021

Accepted: 21 October 2021

Published: 25 October 2021

Publisher's Note: MDPI stays neutral with regard to jurisdictional claims in published maps and institutional affiliations.

Copyright: (c) 2021 by the authors. Licensee MDPI, Basel, Switzerland. This article is an open access article distributed under the terms and conditions of the Creative Commons Attribution (CC BY) license (https:// creativecommons.org/licenses/by/ $4.0 /)$.

\begin{abstract}
In smart manufacturing, human-cyber-physical systems host digital twins and IoT-based networks. The networks weave manufacturing enablers such as CNC machine tools, robots, CAD/CAM systems, process planning systems, enterprise resource planning systems, and human resources. The twins work as the brains of the enablers; that is, the twins supply the required knowledge and help enablers solve problems autonomously in real-time. Since surface roughness is a major concern of all manufacturing processes, twins to solve surface roughness-relevant problems are needed. The twins must machine-learn the required knowledge from the relevant datasets available in big data. Therefore, preparing surface roughness-relevant datasets to be included in the human-cyber-physical system-friendly big data is a critical issue. However, preparing such datasets is a challenge due to the lack of a steadfast procedure. This study sheds some light on this issue. A state-of-the-art method is proposed to prepare the said datasets for surface roughness, wherein each dataset consists of four segments: semantic annotation, roughness model, simulation algorithm, and simulation system. These segments provide input information for digital twins' input, modeling, simulation, and validation modules. The semantic annotation segment boils down to a concept map. A humanand machine-readable concept map is thus developed where the information of other segments (roughness model, simulation algorithm, and simulation system) is integrated. The delay map of surface roughness profile heights plays a pivotal role in the proposed dataset preparation method. The successful preparation of datasets of surface roughness underlying milling, turning, grinding, electric discharge machining, and polishing shows the efficacy of the proposed method. The method will be extended to the manufacturing processes in the next phase of this study.
\end{abstract}

Keywords: big data; surface roughness; digital twin; human-cyber-physical system; artificial intelligence

\section{Introduction}

Smart manufacturing (or Industry 4.0) [1] embarks on a human-cyber-physical system (HCPS) [2], as shown in Figure 1. The HCPS (Figure 1) [2] consists of Internet of Things (IoT)-based manufacturing enablers [3], digital twins (DT) [4,5], big data (BD) [6], and documentation of past research and operational activities.

Like its predecessors, smart manufacturing needs manufacturing enablers such as CAD/CAM systems, process planning systems, CNC machine tools, measuring devices, actuators, robots, and human resources. The difference is that the enablers create an IoT-based network [3], allowing both vertical and horizontal integrations. At the same time, the enablers must perform human-like cognitive tasks [1,5] such as understanding current situations, predicting future consequences, deciding the right courses of action, and adapting to new situations as autonomously as possible. The autonomous execution of the abovementioned cognitive tasks requires a great deal of knowledge $[5,7,8]$ that can be 
extracted from the relevant segments of BD using artificially intelligent systems. Machine learning capacities empower these systems [9]. DTs contain knowledge extraction systems, extracted knowledge, and capacities to perform human-like cognitive tasks [5]. DTs also provide (or receive) feedback to (or from) the IoT-based manufacturing enablers to keep the enablers adaptive to new situations [10].

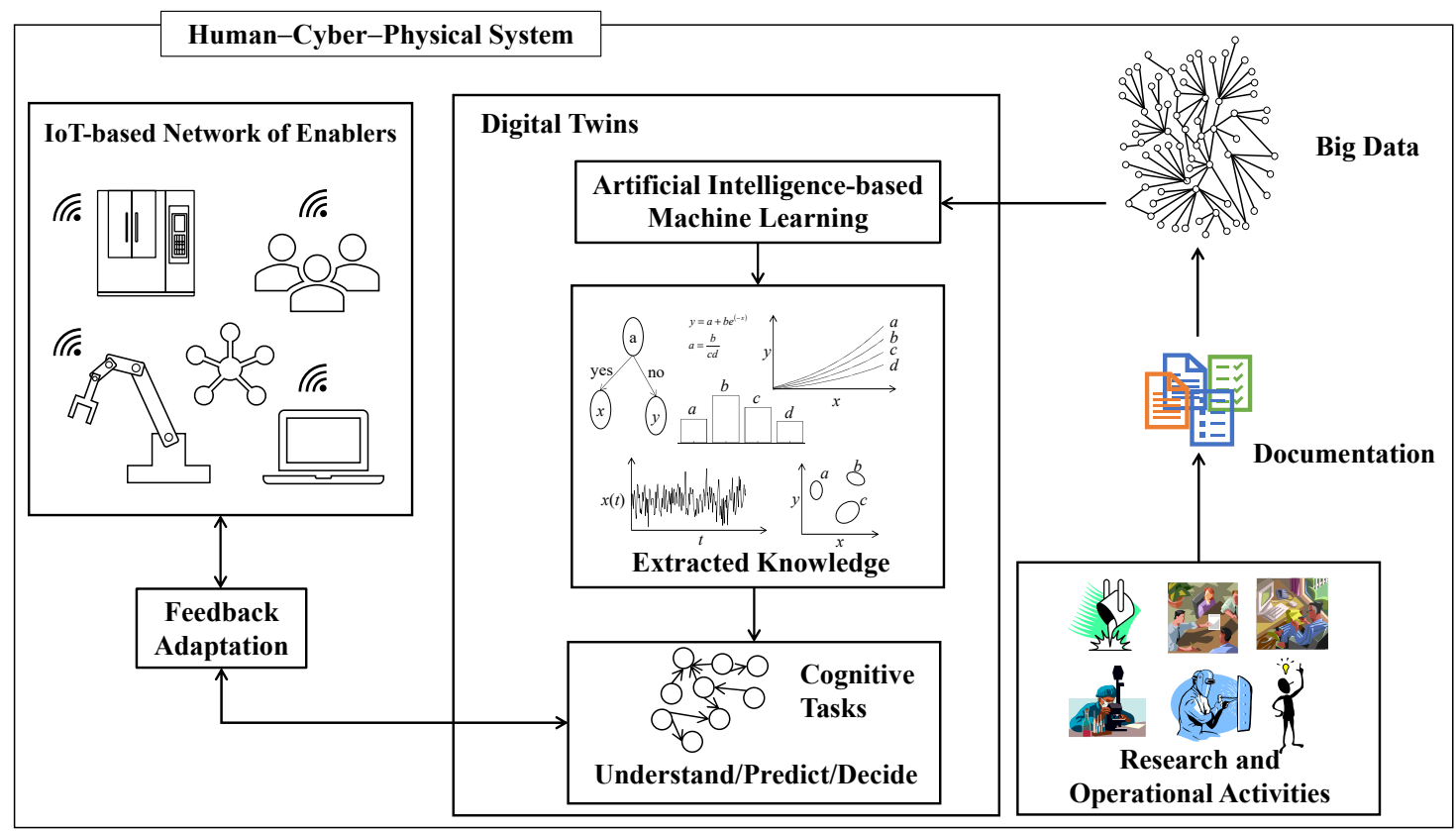

Figure 1. Constituents of smart manufacturing.

Let us focus on BD [6]. Generally speaking, BD consists of a vast array of heterogeneous unstructured, semi-structured, and structured datasets [11,12]. Some datasets can be accessed through the Internet, and some cannot. However, the HCPS-friendly segments of $\mathrm{BD}$ must have the following characteristics. The segments must be readily accessible to all stakeholders, preferably through the Internet. In addition, the segments must be both human- and machine-readable. Moreover, the segments can be effortlessly integrated with the knowledge extraction systems and, thereby, to DT. The segments of BD exhibiting the abovementioned characteristics are not readily available. They need to be prepared using the relevant documentation of past research and operational activities. The documentation is, by nature, messy, and there is no steadfast procedure by which the documentation can be converted into an HCPS-friendly BD. This study sheds some light on this issue. In particular, this study uses the case of surface roughness and elucidates a method for preparing datasets to be included in an HCPS-friendly BD.

Surface roughness $[13,14]$ is a major concern of all manufacturing processes, and ensuring the right surface roughness requires knowledge. In most cases, the required knowledge is extracted from experimental datasets. In an HCPS, a dedicated DT supplies the surface roughness-relevant knowledge to the manufacturing enablers. However, before a DT supplies the required knowledge, it must be constructed. (See Section 3 for more details.) The question is, from where does the DT collect the information? The obvious answer is that BD supplies the information. In other words, BD must host datasets useful for building a DT. Consequently, a mere digitized version of the documentation of experimental and operational activities (Figure 1) is not enough to build BD; datasets needed to build DT must be added to BD. Otherwise, BD may not be useful for the HCPS. Based on this consideration, this article is written.

The rest of this article is organized as follows. Section 2 briefly reviews selected publications on big data for smart manufacturing, highlighting the methods currently used to construct and functionalize BD and analytics. Section 3 presents the different types of 
datasets often used to document research and operational activities of surface roughness. This section also highlights the current utilization level of surface roughness datasets in cyberspace. Section 4 presents a method for preparing datasets of surface roughness to be included in BD for making it (BD) meaningful to DT. This section also articulates the major issues, the structure and segments of the datasets, and their interplay with DT. Section 5 presents some noteworthy results when the proposed method is applied to preparing datasets of the roughness of turning, milling, grinding, electric discharge machining, and polishing. Section 6 concludes.

\section{Literature Review}

This section briefly reviews selected publications on big data for smart manufacturing. The goal is to highlight the methods currently used to construct and functionalize BD and relevant analytics. The research gaps are highlighted in Section 4 , however.

Moktadir et al. [15] studied the barriers of BD implementation in real-life manufacturing organizations located in a developing economy. They found that collecting reliable datasets from relevant sources is the most significant barrier. The second most significant barrier is related to technology and resource-lack of IT infrastructure, data privacy assurance, complexity in data integration, lack of appropriate BD analytics, and high investment. As far as a developed economy is concerned, similar barriers still exist, as reported in [16,17].

Syafrudin et al. [18] proposed a real-time monitoring framework of manufacturing systems focusing on the automotive industry. The framework utilizes BD collected from IoT-based sensors and processes it (BD) by a hybrid prediction model. In particular, unstructured datasets collected from manufacturing processes by temperature, humidity, accelerometer, and gyroscope sensors were preprocessed using platforms known as Apache Kafka (message queue), Apache Storm (real-time processing engine), and MongoDB (data storage). Subsequently, density-based spatial clustering with noise removal capacity was used to detect outliers and to classify data for fault detection. They proposed BD-driven system to prevent unexpected losses caused by faults during manufacturing automotive parts and performing assembly operations.

Wiech et al. [19] considered that BD analytics and manufacturing execution systems are needed to achieve the objectives of Industry 4.0. They studied the implementation levels of BD analytics and manufacturing execution systems by conducting a survey in which more than one hundred organizations participated. They found that the BD analytics and manufacturing execution systems are heavily correlated, and the performance is not likely to depend on organizational structures.

Escobar et al. [20] conducted a literature review to understand the interplay of $\mathrm{BD}$ and process monitoring for quality control from the context of Industry 4.0 (i.e., Quality 4.0). They proposed that manufacturing BD-centric challenges can be tackled by implementing a seven-step approach: identify, accessorize, discover, learn, predict, redesign, and relearn. In addition, they found that a vast array of process datasets collected either from plants or from laboratories in the form of pictures, signals, and direct measurements can be analyzed in real-time using simple machine learning algorithms rather than deep learning.

Yu et al. [21] presented a BD ecosystem for predictive maintenance. The data sources were the sensor signals collected from large-scale manufacturing plants. The ecosystem used numerous technologies (data lake, NoSQL database, Apache Spark, Apache Drill, Apache Hive, and OPC Collector) to solve data ingestion, integration, transformation, storage, analytics, and visualization. In addition, the required transformation protocols, authentication, and encryption methods were also addressed to secure the data transfer. Finally, a Map-Reduce decentralized principal component analysis made sense of BD for predictive maintenance. The Map-Reduce decentralized principal component analysis, which is simple and can respond faster on a real-time basis, was used to make sense of sensor signals for predictive maintenance. 
Faheem et al. [22] considered that sensor datasets collected by a wireless sensor network from various sources (equipment, machines, assembly lines, material handling devices, and inspection activities) constitute industrial $\mathrm{BD}$. The datasets are subjected to trigger errors and low transmission quality due to high noise, signal fading, multipath effects, heat, and electromagnetic interference. In order to solve the abovementioned problems, they introduced a multi-channel and multi-radio architecture denoted as CBI4.0. As confirmed by an EstiNet 9.0 simulator, the proposed architecture exhibited robust performance compared with other wireless sensor signal networks used to support BD in the automotive industry.

O'Donovan et al. [23] presented data requirements, system requirements, and information system models for utilizing BD in equipment maintenance. The goal was to provide a scalable and fault-tolerant $\mathrm{BD}$ pipeline for integrating, processing, and analyzing datasets relevant to industrial equipment. The focus was on the highly automated large-scale manufacturing environments in which Internet-aware smart sensors play a vital role.

Shah et al. [24] showed that BD of sensor signals collected from IoT-networked manufacturing devices effectively modeled and monitored manufacturing processes. However, to make sense of a large array of datasets, machine learning techniques must be employed. In particular, they developed an IoT-based testbed capable of handling BD (about 70 GB) underlying a pipe flow system coupled with five IoT-based vibration sensors. Furthermore, they compared the complex deep learning models with simple statistical learning models in processing the sensor signals. They identified that simple statistical learning could achieve superior results over deep learning because there are still unsolved challenges making deep learning less effective.

On the contrary, Fang et al. [25] showed that deep learning is more effective than other machine learning (e.g., linear regression, back-propagation, and multi-layer and deep belief networks) in making sense of manufacturing $\mathrm{BD}$ when predicting the remaining time to complete a part. They used BD collected from various sensors in a large-scale job shop equipped with 44 machines producing 13 types of parts. The proposed framework needs raw data collection, candidate dataset design and selection, and predictive modeling using a deep learning approach denoted as a stacked sparse autoencoder.

Zhang et al. [26] proposed an energy-aware cyber-physical system in which energyrelated $\mathrm{BD}$ and production-related $\mathrm{BD}$ play a vital role. The datasets were originated from energy monitors (sensors) mounted on machine tools and on gas, liquid, and cutting fluid circulation devices. Before making sense of these datasets, they were cleaned by removing the noise and abnormalities. Finally, deep belief networks classified the continuous energy consumption data according to different machining states, which helped ensure low energy consumption.

Ko and Fujita [27] developed evidential analytics for unearthing the buried information in BD samples, focusing on the manufacturing of semiconductors. They found that raw datasets in BD often exhibit undesirable characteristics such as unspecified sampling principles and analytics baselines, a large number of redundant variables or features, a mixture of relevant and irrelevant datasets, indistinguishable noise, and outliers in datasets. $\mathrm{BD}$ analytics must handle these characteristics and identify the causes of damage beforehand. To achieve this, they proposed analytics denoted as evidential analytics for buried information (EABI) that used the concept of granular information. EABI consists of three phases. The first phase generates baselines expressing the relevance to damages in the directions of high and low for reducing the number of variables. The second phase unearths the preference and relevance together. The last phase aggregates evidence among variables for evaluating the samples.

\section{Surface Roughness Data}

As described in the previous section, the root of all problems associated with constructing BD and its utilization is the datasets themselves [15-17,22,27]. Thus, before presenting the proposed method for preparing the datasets to be included in BD of surface roughness, 
it is important to see how and what kind of datasets of surface roughness are often documented after performing experimental and operational activities. This section serves this purpose.

Nowadays, surface roughness $[13,14]$ is measured by laser-based non-contact surface metrology instruments [28], as shown in Figure 2a. This type of instrument moves a laser source on the surface to be measured in a definite trajectory, as shown in Figure 2b. For this, the instrument first sets an $x y$-mesh (Figure 2c) and obtains the height information of the surface (Figure 2d). In addition to height information, the instruments can represent a mesh using a pixel [29]. As such, two types of information are produced. One of the types consists of a 3D surface based on height information (Figure 2e,f).
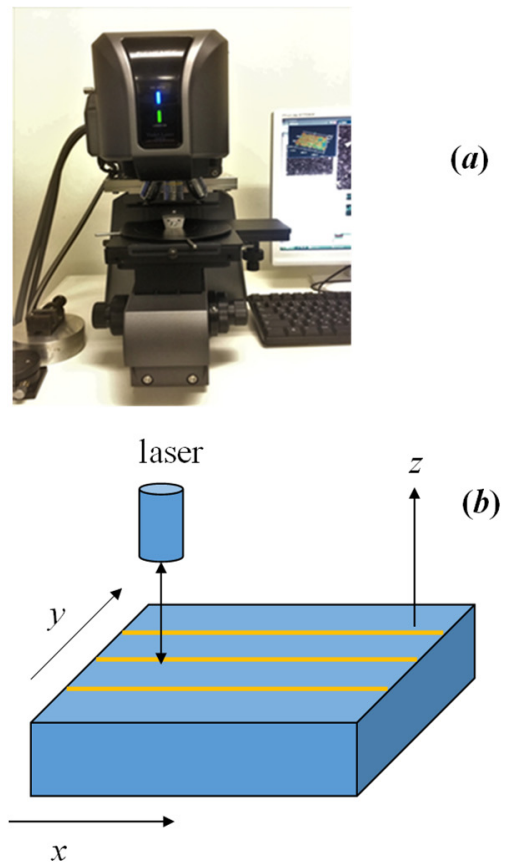

(a)

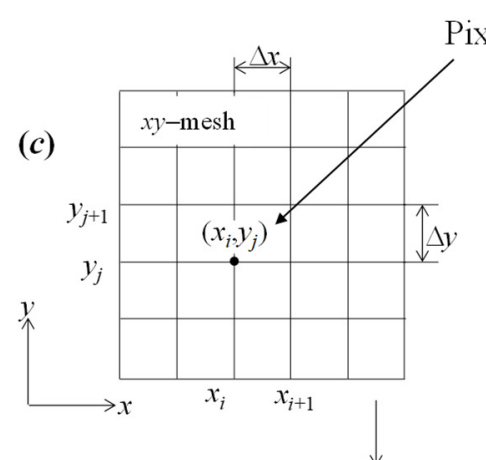

(d)

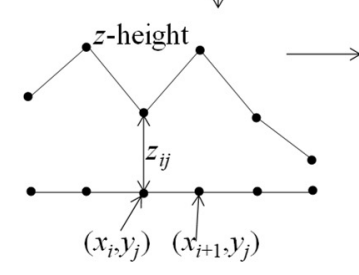

Pixel

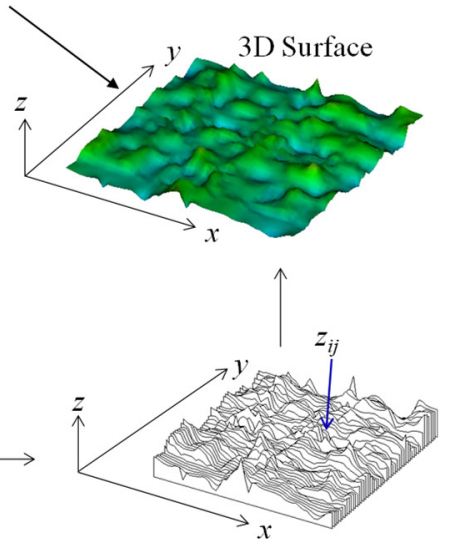

$z$-height representation (e)

Figure 2. Measuring surface roughness. (a) Surface metrology equipment; (b) Measurement; (c) Two-dimensional mesh; (d) Surface height dataset; (e) Rendering 3D surface of measured surface; (f) 3D height rendering of measured surface.

The other is the images of the measured surface, as shown in Figure 3a-c. In particular, Figure 3a shows a raw image of an arbitrary surface [29]. Figure $3 b$ shows a binary image [29]. This image is extracted from the image shown in Figure $3 a$ and carries valuable topographical information of the surface [29]. Figure 3c shows a color image in which different heights are depicted using different colors (height gradation image). This is also useful for surface topography analysis. Figure 3d shows a 3D surface rendered from the height datasets using a curve-smoothening technique. Figure $3 e$ shows a height profile (surface profile) of the surface for a given $y$ (or $x$ ) along the $x$ (or $y$ ) direction [28]. A primary profile (not shown in Figure 3) is obtained by removing linear or curved "form error" underlying the surface height profile $[14,28]$. Figure $3 f$ shows a surface roughness profile obtained by removing the waviness from a primary profile. 
(a)

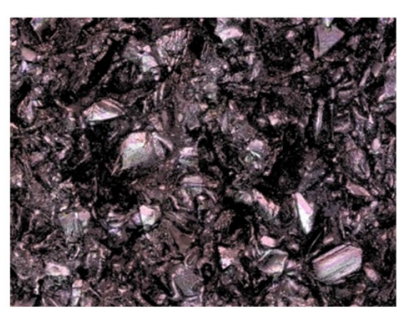

(d)

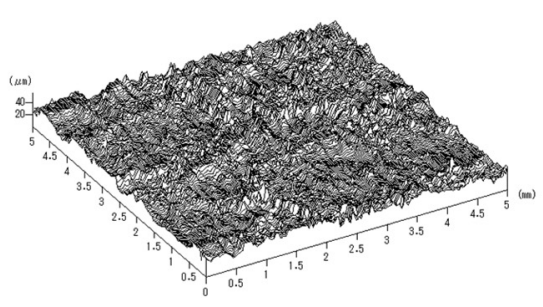

(b)

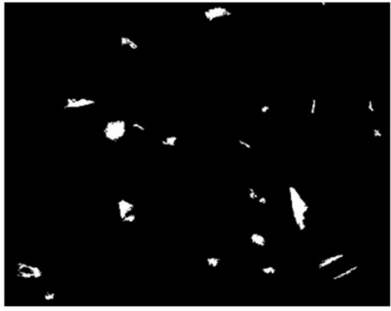

(e)

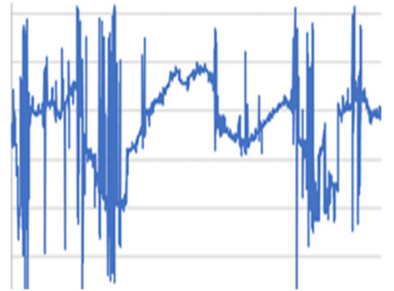

(c)

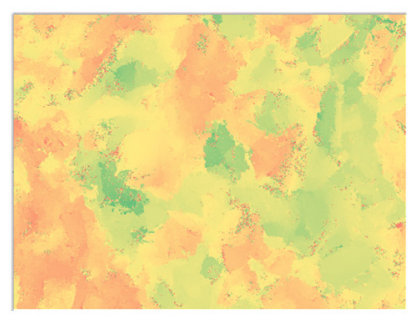

$(f)$

Figure 3. Different types of datasets of surface roughness. (a) Surface image; (b) Binary image obtained from (a); (c) Hight gradation image; (d) 3D rendering of heights; (e) Surface profile; (f) Surface roughness profile.

An online system developed by the NIST of the USA [14,30] (see Figure 4) supports the surface height processing as mentioned above.

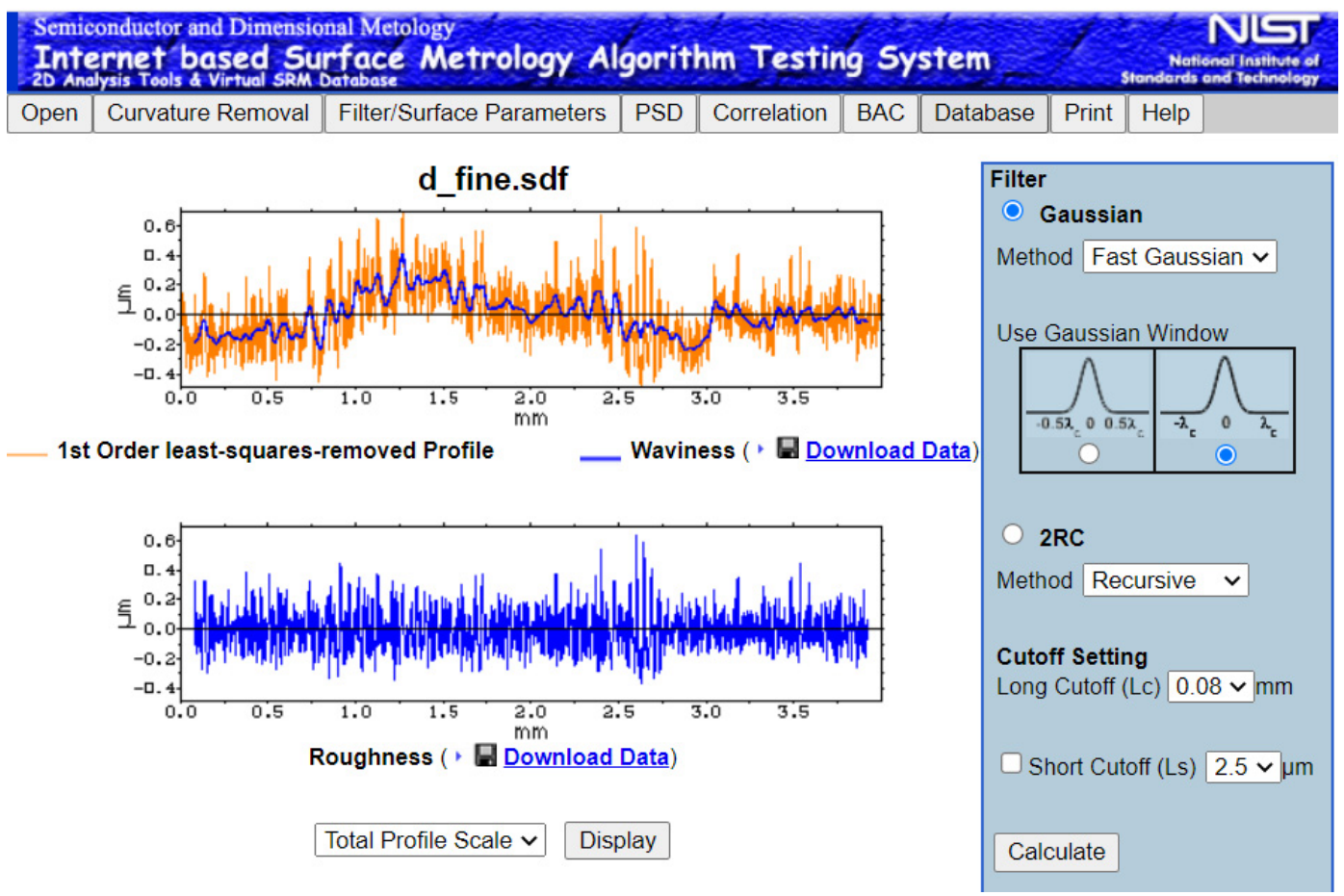

Figure 4. Existing Internet-based surface roughness system.

The system $[14,30]$ provides a user interface (Figure 4) for uploading a raw surface profile dataset. The system then uses the standard procedures and calculates parameters, including $R a$ and $R z$ [14,28,30]. Instead of using the standard parameters, advanced parameters such as fractal dimension, surface entropy, and possibility distributions [30] can be used to accurately quantify the complexity of surface roughness. For calculating the advanced parameters, the surface profile height datasets must be retained in BD. Thus, 
Extensible Markup Language (XML)-based datasets in which the information of $R a$ and $R z$, only, is retained, as shown in [31], require a revisit.

\section{Preparing Datasets of Surface Roughness for BD}

In Section 2, using the literature review [15-27], the scope of limitations of BD from the perspective of Industry 4.0 is described. In synopsis, the following remarks can be made.

(a) The raw or proposed datasets added to BD may not be able to bring benefits to smart manufacturing if the targeted usages of the datasets are not considered in the first place. This means that the datasets regarding surface roughness, as shown in Section 3 (Figure 3), should not be added directly to construct BD of surface roughness. Instead, the datasets must be preprocessed based on the targeted use before adding them to the $\mathrm{BD}$ of surface roughness.

(b) There is no steadfast approach available for preprocessing raw datasets collected from real-time sensor signals or past experimental and operational activities for building BD.

(c) Large organizations having the strength to maintain sophisticated IT infrastructures (for example, the automotive industry and chemical industry) can execute sophisticated BD analytics. However, an opposite scenario prevails for small- and mediumsized organizations.

(d) The effectiveness of well-known machine learning approaches while making sense of $\mathrm{BD}$ is controversial. For example, some authors advocate complex machine learning approaches (artificial neural networks-driven machine learning such as deep learning); others advocate rather simple ones.

Therefore, many open questions remain regarding how to construct and functionalize $\mathrm{BD}$ for smart manufacturing. In order to address the abovementioned problems in a befitting manner, this section presents a method that can be used to prepare the datasets of $\mathrm{BD}$ of surface roughness from the context of an HCPS. Before presenting the proposed method, three salient issues (BD inequality, semantic annotation, and DT) are presented as follows.

First, consider the issue of BD inequality [32]. Recall that BD consists of a vast array of heterogeneous datasets (unstructured, semi-structured, and structured) that evolve with time [11,12]. Arrangements for extracting knowledge from a relevant segment of $\mathrm{BD}$ are computationally heavy and highly resource-dependent as well. As a result, BD benefits large organizations. Medium and small organizations fall behind. This results in BD inequality [32]. Unfortunately, studies dealing with BD integration with an HCPS, e.g., [33-36], have not yet addressed BD inequality. For example, consider the work in [33]. The authors formulated $\mathrm{BD}$ analytics, where the $\mathrm{BD}$ is integrated with machine learning and computational intelligence paradigms. The arrangement requires highly sophisticated computing devices and highly skilled human resources. As such, these systems are beyond the affordability of medium and small organizations. One way to minimize the involvement of sophisticated computing devices and highly skilled human resources is addressing how the datasets are prepared in the first place. Care should be taken while developing dataset preparation methods so that the methods help mitigate BD inequality.

Second, consider the issue of semantic annotation or metadata. It (semantic annotation or metadata) has become a crucial issue due to the advent of web technology, and many authors have contributed toward semantic annotation or metadata [37-45]. The fact of the matter is that the new web technology called Semantic Web (SW) [46] is in the process of replacing its predecessor. SW-based datasets need both the datasets themselves and "data about datasets". This "data about datasets" is referred to as semantic annotation or metadata. As a result, all relevant datasets can be gathered quickly-the search engines become more effective-which is not the case now. At the same time, the semantic annotations facilitate the amalgamation of relevant datasets scattered in different information silos. However, for constructing metadata, different types of ontological approaches are proposed in the literature. Most of the approaches depend heavily on the query language 
and data access protocol (e.g., SPARQL) customized for the resource description framework (RDF) [47]. As a result, the current semantic annotation preparation approaches are unscalable and esoteric. Making the semantic annotation preparation approaches more user-friendly and scalable and less esoteric is a challenge. This challenge can be overcome if natural language-based semantic annotations are used, ensuring the freedom of using any phrases that the users prefer. In this respect, concept mapping is the right approach, as shown in $[5,48]$.

Last, consider the case of DT (Figure 1). By definition, DTs are the computable virtual abstractions of real-world objects, processes, and phenomena $[5,39]$. They have real-time response capacity. As mentioned, DTs host knowledge extraction systems, knowledge-base, and human-like cognitive tasks and provide (or receive) feedback to (or from) the IoT-based manufacturing enablers. They keep the enablers adaptive to new situations. Thus, they serve as the brains of the IoT-based enablers. Since surface roughness is a manufacturing phenomenon, a DT dealing with surface roughness is a phenomenon twin. A phenomenon twin (of surface roughness) consists of five modules: input module, modeling module, simulation module, validation module, and output module [49]. The input module extracts information from a source (e.g., BD) for building other modules. The modeling module models a phenomenon. The simulation module simulates the expected outcomes of the phenomenon upon request from the respective enablers. The validation model validates the integrity of results produced by the twin. Finally, the output module integrates the twin with the relevant IoT-embedded enablers. See $[49,50]$ for more details.

Considering the issues of BD inequality, semantic annotation, and DT, a BD preparation method is proposed, as schematically illustrated in Figure 5. As seen in Figure 5, a dataset of BD consists of four segments denoted as semantic annotation, roughness model, simulation algorithm, and simulation system. These segments can be downloaded while developing a DT of surface roughness.

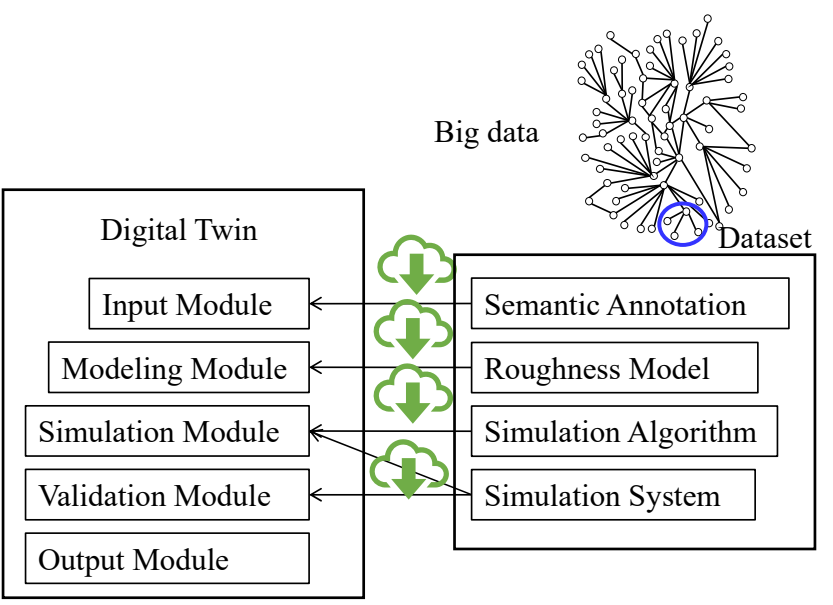

Figure 5. Proposed dataset preparation method.

The segment denoted as semantic annotation provides information for the input module of the digital twin. The segment denoted as the roughness model provides information for the modeling module of the digital twin. The segment denoted as the simulation algorithm provides information for the simulation module of the digital twin. The segment denoted as simulation system provides information for both the simulation and validation modules of the digital twin. There are no segments in a dataset that provide information for the output module of the digital twin. Based on the proposed method, a set of datasets of surface roughness is constructed for different types of material processes such as turning, milling, grinding, polishing, and electric discharge machining. The results regarding grinding are shown in the next section. 


\section{Results and Discussions}

This section presents the noteworthy results obtained using the proposed method and discusses the results' implications.

For better understanding, the roughness model segment of the dataset is presented first, as follows. The roughness model segment presents the information of the delay map of a roughness profile. Two pieces of information are stored. The first is the roughness DNA, and the other is two sets of possibility distributions induced from the delay map. For this, the following formulation is considered. Let $x(i) \in[0,1], i=0,1, \ldots$, be the normalized heights of a measured surface. A delay map consists of the ordered-pair $(x(i), x(t+d))$, $i=1,2, \ldots$, where $d$ denotes the delay, a non-zero integer. Let $S_{j}, i=1,2, \ldots, M$ be the states of roughness dividing the interval $[0,1]$ into $M$ mutually exclusive intervals. The states of $x(i)$ are represented by a roughness DNA $=(S i \mid i=0, \ldots, N)$ so that $\forall S i \in\{S j \mid j=$ $1, \ldots, M\}$. The abscissa of the delay map is represented by the triangular fuzzy numbers $(a 1(S j), b 1(S j), c 1(S j)), j=1, \ldots, M$, where $[a 1(S j), c 1(S j)]$ is the range of $S j$, and $b 1(S j)$ is the midpoint of $S$ j. The ordinate of the delay map is represented by the triangular fuzzy number $(a 2(S j), b 2(S j), c 2(S j)), j=1, \ldots, M$, where the support $[a 2(S j), c 2(S j)]$ and core $b 2(S j)$ are determined using the probability-possibility transformation applied to the map, as defined in [51]. Figure 6 shows a typical surface roughness model.
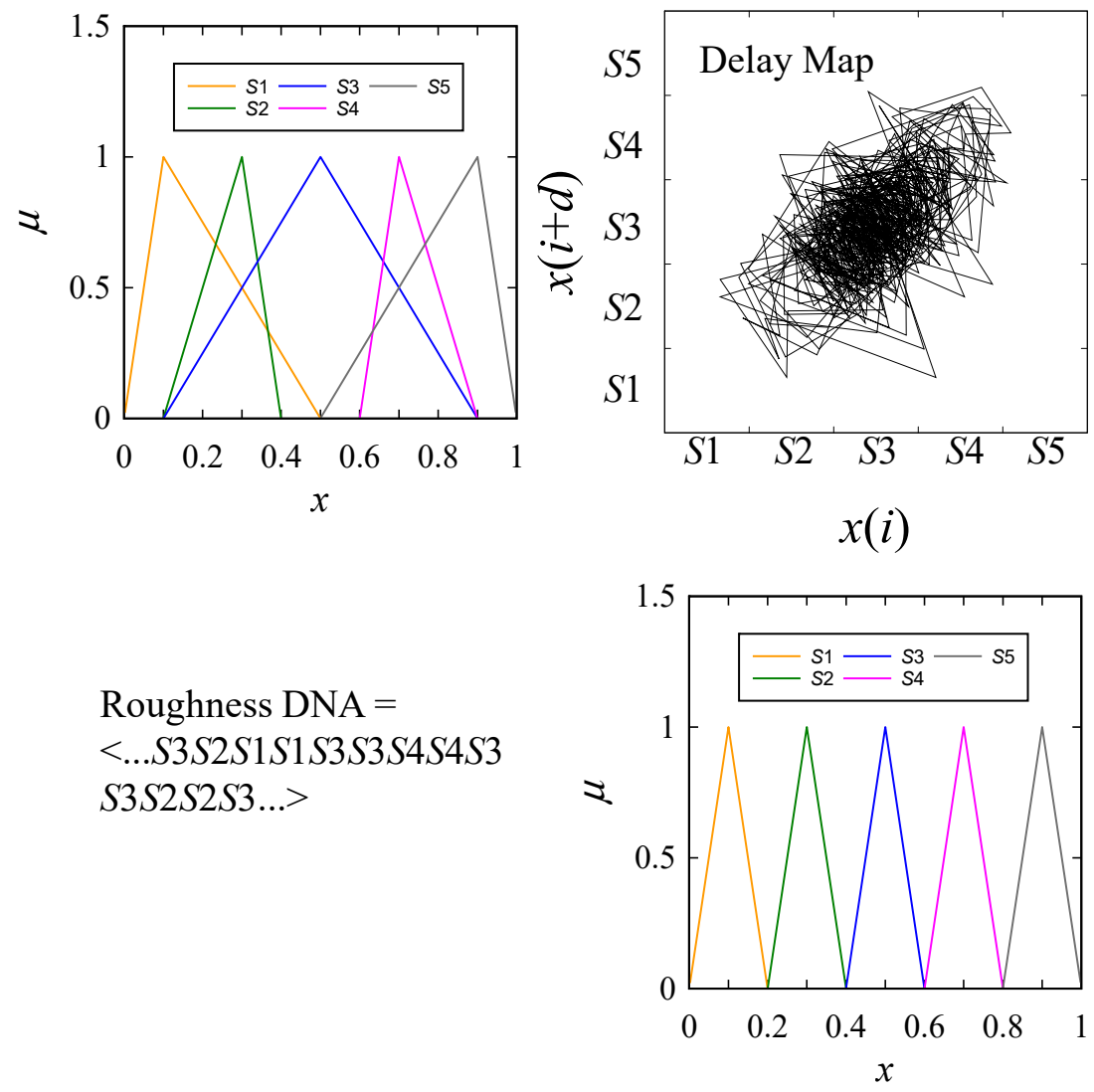

Figure 6. Constituents of roughness model.

Note the presence of two sets of possibility distributions and the roughness DNA. The case shown in Figure 6 corresponds to five-state modeling, S1, . , S5, where $M=5$. The simulation algorithm is shown by Algorithm 1 (Surface Profile Simulation). 


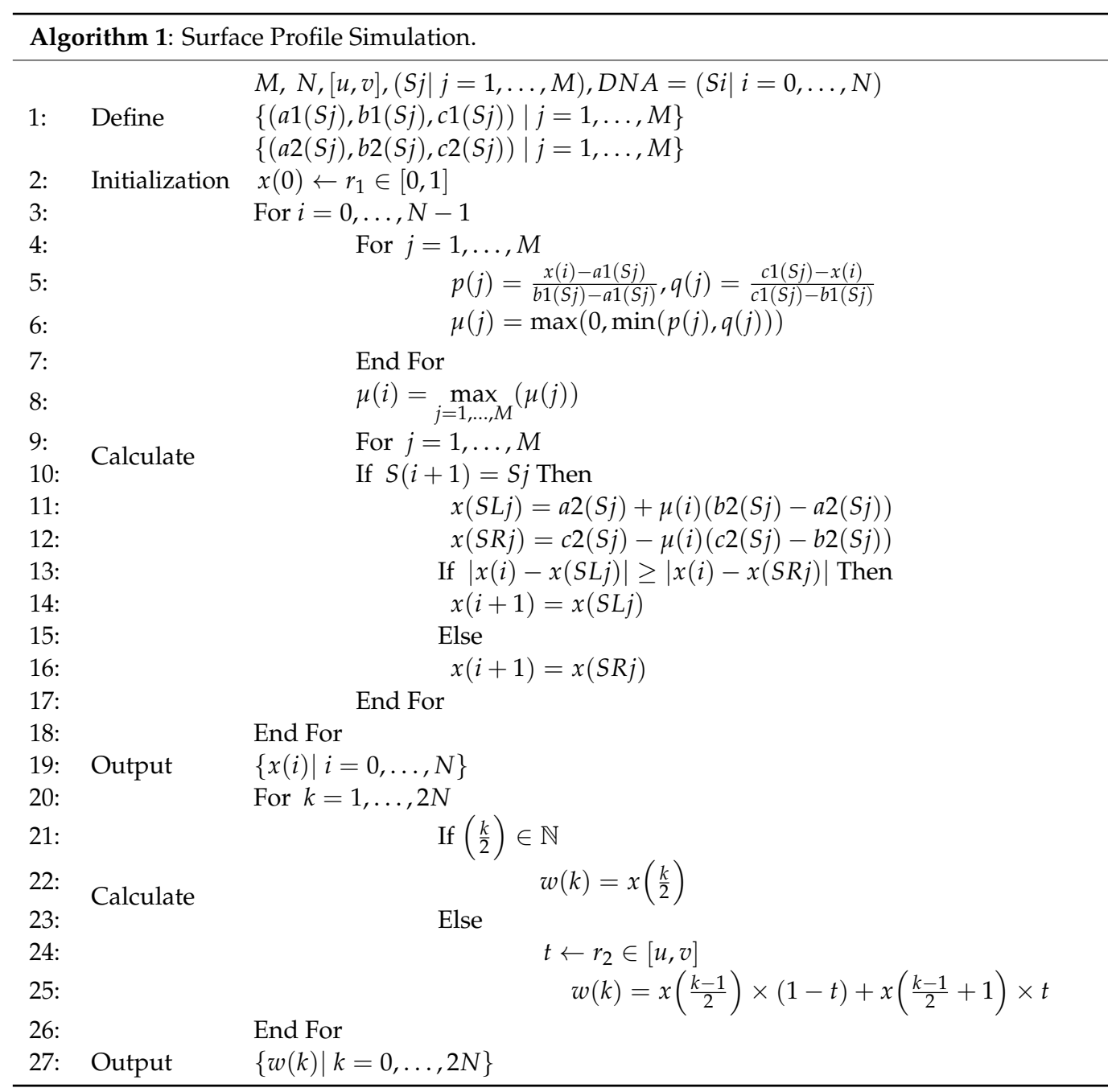

The calculation processes associated with Algorithm 1 are schematically illustrated in Figure 7. As seen in Figure 7, the simulation process acknowledges the roughness model (roughness DNA, possibility distributions, definitions of states). It initializes the roughness height $x(0)$ by a random number $r_{1} \in[0,1]$. After that, it calculates the maximum degree of belief and sets it as $\mu(0)$ from the fuzzy numbers assigned to the abscissa. It then calculates the values denoted as $x(S L j)$ and $x(S R j)$ for the state $S i$ (this time, $i=1)$ dictated by the roughness DNA, as schematically illustrated in Figure 7a. The algorithm then chooses one of the calculated values that is the most far from $x(0)$ compared with the other and assigns it as $x(1)$. This way, the simulation algorithm continues its simulation process for all $i=0, \ldots, N$. This results in simulated roughness heights $x(i), i=0, \ldots, N$. The simulated heights are linearly interpolated according to steps $20, \ldots, 26$, as schematically illustrated in Figure $7 \mathrm{~b}$. As seen Figure $7 \mathrm{~b}$, two consecutive heights, $x(i)$ and $x(I+1)$, are linearly interpolated using a random value $r_{2} \in[u, v]$, where $u \leq 0$ and $v \geq 1$. This results in a new time series $w(k), k=0, \ldots, 2 N$, where $x(k)=x(k / 2)$ if $k$ is an even number, and $w(k)$ is the interpolated value when $k$ is an odd number. Therefore, the outcomes, $w(k), k=0, \ldots, 2 N$, are the simulated surface roughness models. 
(a)

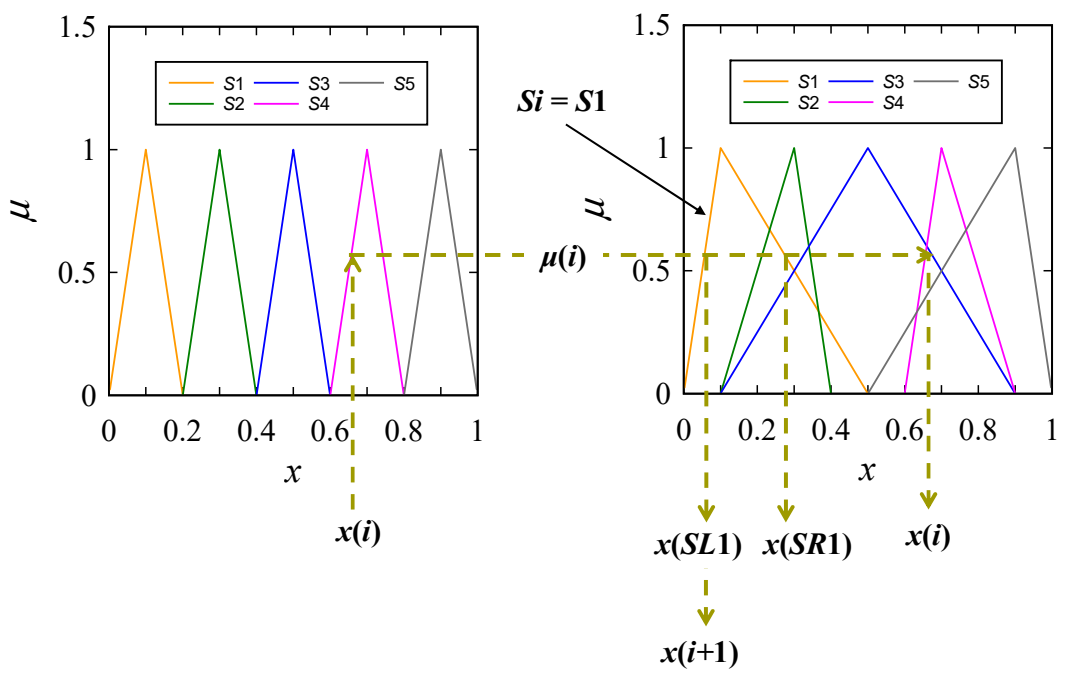

(b)

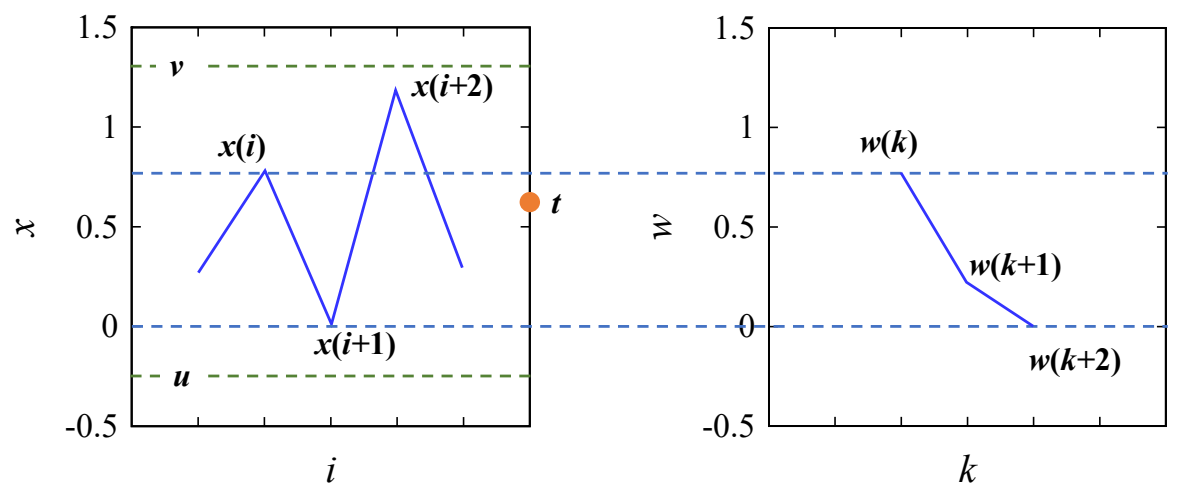

Figure 7. Illustrations of steps $3, \ldots, 27$ of Algorithm 1 .

The segment coupled with the simulation algorithm segment is the simulation system because the system is developed using the simulation algorithm. The simulation system must be kept simple to mitigate the BD inequality (see Section 4). At the same time, it must be executable by many stakeholders, including those who belong to medium and small organizations. Based on this consideration, the authors used a spreadsheet-based computer program to build the simulation system; one of the user interfaces is shown in Figure 8. As seen in Figure 8, the user can set a delay and input the data points of surface roughness heights. The system simulates the surface roughness heights. The similarity between the simulated and real surface roughness heights can be compared in terms of time series, delay maps, and possibility distributions, as shown in Figure 8. 


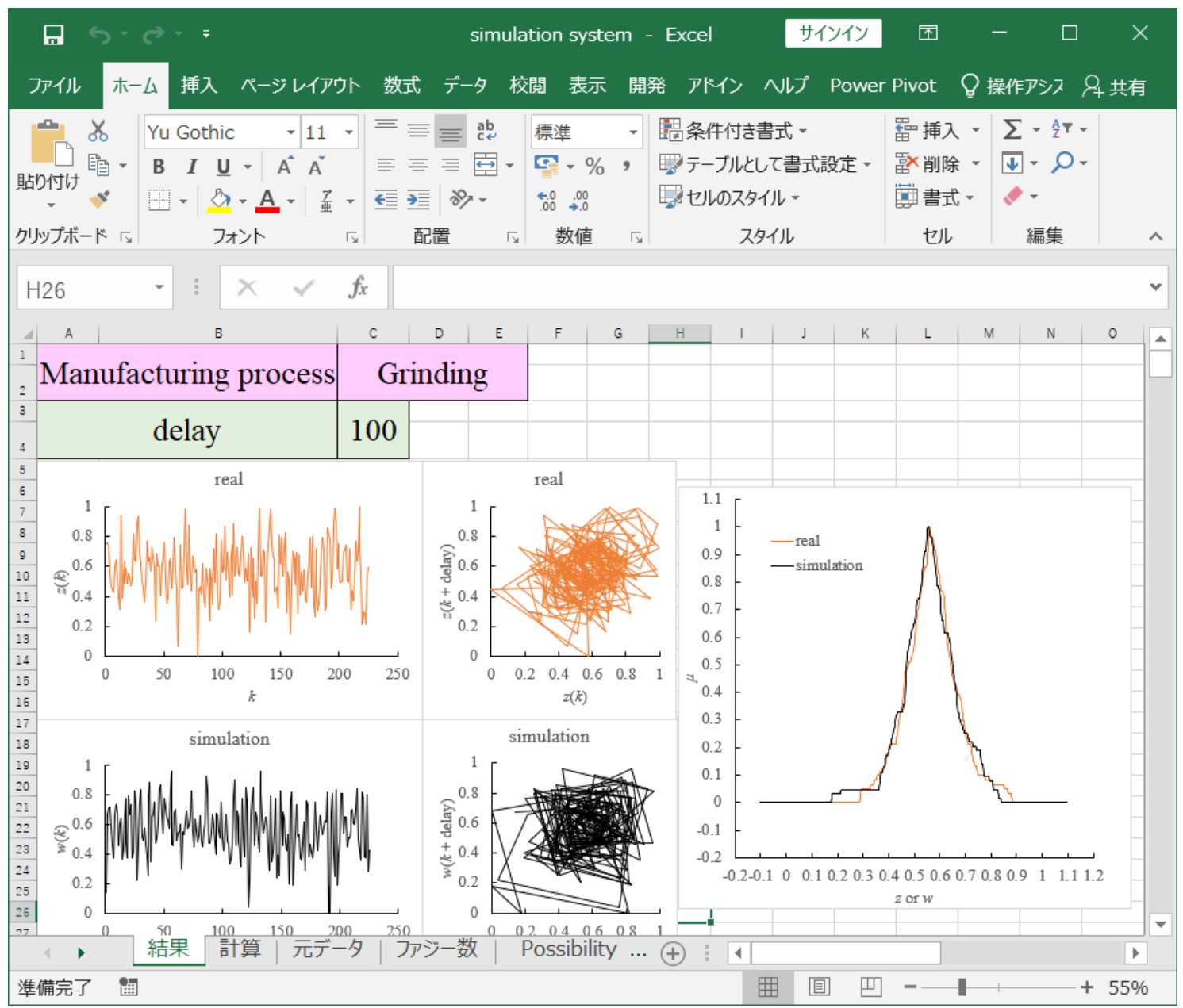

Figure 8. A user-interface of the simulation system.

The contents shown in Figures 6-8 do not incomplete the dataset of surface roughness for constructing BD. The semantic annotation segment must be added to complete the dataset. This segment (semantic annotation) becomes the face of the dataset. It integrates other segments shown in Figures 6-8. At the same time, the XML codes generated from the semantic annotation link the BD to a DT and other constituents of the HCPS. The remarkable thing is that the semantic annotation segment manifests a concept map (a user-defined ontology of the issue considered). Before constructing the concept map, a set of proposition blocks (PBs) must be considered expressed by natural language (here, English). The number of propositions depends on the individuals who construct them. Some of the PBs provide a general description, and some others represent the dataset segments. PBs share some common concepts, resulting in a concept map.

Here, a seven proposition-based set of PBs for constructing the semantic annotation segment of the dataset are considered. These PBs are listed in Table 1.

Table 1. Proposition blocks for concept mapping.

\begin{tabular}{cc}
\hline Blocks & Propositions \\
\hline PB1 & $\begin{array}{r}\text { Surface roughness profile heights of a manufacturing process called }<\text { name of the } \\
\text { process }>\text { produces a delay map }\end{array}$ \\
\hline PB2 & Abscissa and ordinate of the delay map are divided by some fuzzy numbers \\
\hline PB3 & Delay map entails a roughness DNA \\
\hline
\end{tabular}


Table 1. Cont.

\begin{tabular}{cc}
\hline Blocks & Propositions \\
\hline PB4 & $\begin{array}{r}\text { Surface roughness profile heights are simulated using a simulation, producing } \\
\text { simulate roughness profile heights }\end{array}$ \\
\hline PB5 & Simulated roughness heights can be further processed by linear interpolation \\
\hline PB6 & Simulation process and linear interpolations underlie a simulation algorithm \\
\hline PB7 & Simulation algorithm manifests a simulation system \\
\hline
\end{tabular}

The resulting concept map is shown in Figure 9. This map is the semantic annotation segment of the surface roughness dataset to be added to BD. The URL of this annotation is https: / / cmapspublic2.ihmc.us/rid=1WYZG3ZMM-1SZ8JR8-41S0/surface-roughness\% 20datasets\%20for\%20big-data.cmap (accessed on 20 October 2021). It can be accessed through the Internet. The annotation also carries the roughness DNA, fuzzy numbers of the return map, simulation algorithm, and the simulation system, which can be downloaded for reuse (for building DT of surface roughness). Alternatively, XML code of the annotation can be generated to use the code in an IoT-based enabler network directly.

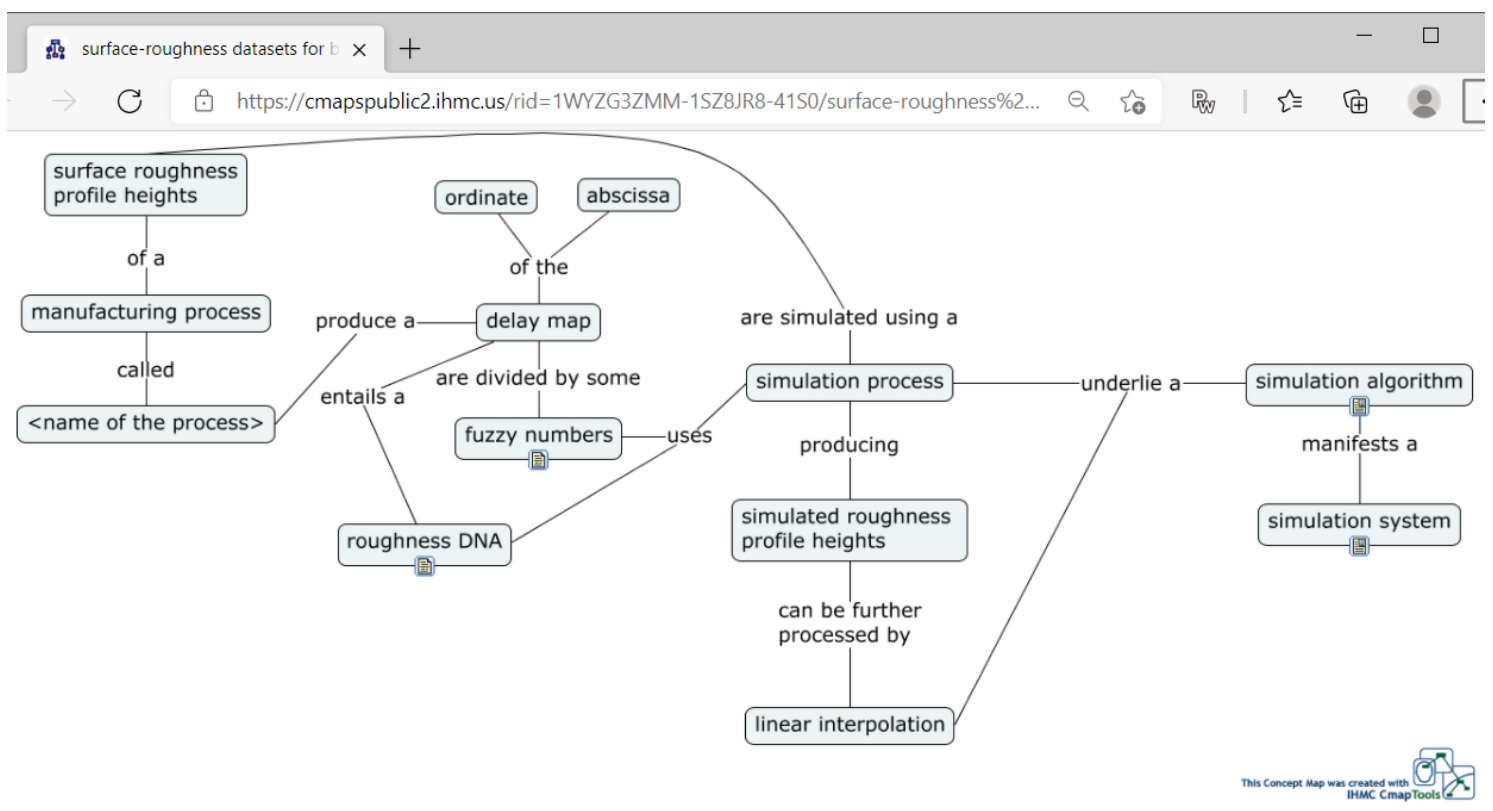

Figure 9. Semantic annotation (concept map) segment of the dataset.

Note that other methods can also model chaotic data points such as surface roughness heights: Markov chain, DNA-based computing, non-stationary Gaussian process, semantic modeling, and the like [49]. The roughness model, simulation algorithm, and simulation system segments are in accord with the modeling method. Even though the dataset segments are reconstructed according to the modeling method, the dataset structure remains the same. Thus, the dataset structure (semantic annotation, roughness model, simulation algorithm, and simulation system) serves as the metadata of the surface roughness.

\section{Security Assurance}

Security assurance in Industrial Internet of Things (IIoT) is a critical issue. The datasets prepared by the presented data preparation method help assure security. For understanding the interplay of security assurance and presented dataset preparation method, consider Roughness DNA (one of the elements of the roughness model) and the provenance layer of the Semantic Web (SW), as schematically illustrated in Figure 10. The concept of SW has been proposed for smoothly exchanging and reusing information among large information 
silos [52]. The main idea is to extend the potency of the Web with an analogous extension of the human's cognitive process [52,53]. SW consists of four layers-syntax layer (XML, URI, and Unicode), semantic layer (ontology and RDF), provenance layer (rule, logic, proof, and trust), and application layer [53]. The syntax layer encodes datasets to be exchanged. The semantics layer provides the meaning of the datasets. The provenance layer ensures the trustworthiness of the datasets for reuse. Finally, the applications layer hosts the applications by which the users (humans and other systems) exchange and reuse the information. The XML code produced from the semantic annotation (Figure 9) populate the syntax layer. Similarly, the semantic annotation itself provides the information for the semantics layers. Finally, some segments of the Roughness Model (Figure 6) can be used in the provenance layer. In this case, Roughness DNA can be input to a DNA-Based Computing (DBC) $[54,55]$ system to see the integrity of the datasets to be transferred to digital twins of surface roughness. It has been shown that a DBC system effectively builds trust in the content related to the manufacturing process. Consequently, a DBC system can help achieve a trustworthy exchange of content. This phenomenon is referred to as pragmatic adaptation of resources from one working environment (big data) to another (digital twin). See [54,55] for more details. It is worth mentioning that as a consequence of the biologicalization of manufacturing, representation of manufacturing data and knowledge using DNA-like information has earned a great deal of attention $[29,56]$.

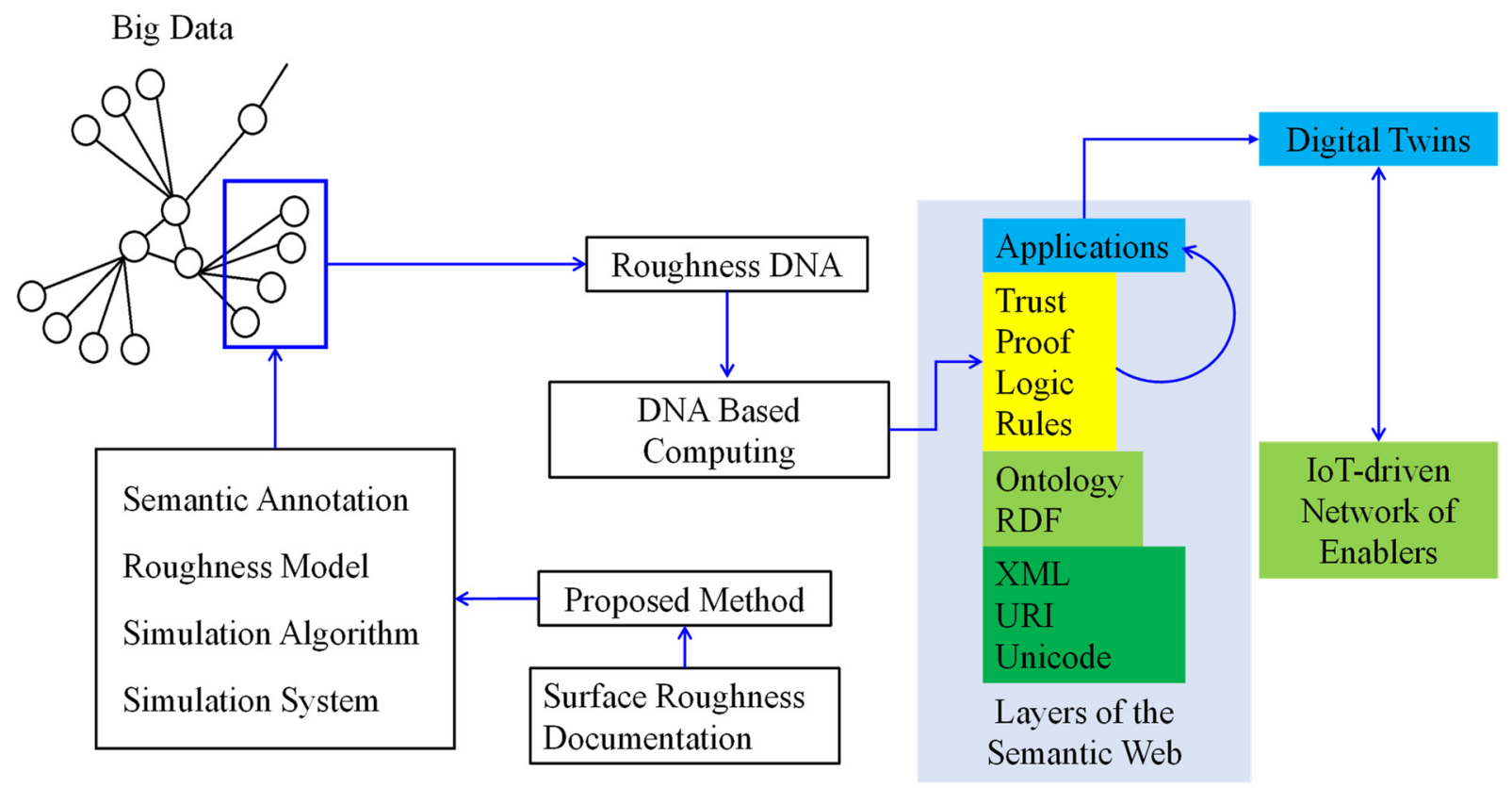

Figure 10. Aspects of security assurance.

\section{Concluding Remarks}

The datasets included in human-cyber-physical system-friendly BD must have the following three characteristics: (1) The datasets must be readily accessible to all stakeholders through the Internet; (2) The datasets must be both human- and machine-readable; (3) The datasets can effortlessly be integrated with the machine-learning-based knowledge extraction segment of a digital twin. Unfortunately, BD exhibiting the abovementioned characteristics is not readily available. Thus, it (BD) needs to be prepared from the documentation of past research and operational activities. This is a challenge because of the lack of a steadfast procedure. This study fills this gap by presenting a state-of-the-art method for preparing the datasets of surface roughness to be included in industrial $\mathrm{BD}$ from the context of smart manufacturing and cognitive computing.

The surface roughness datasets included in human-cyber-physical system-friendly BD consist of four segments: semantic annotation, roughness model, simulation algorithm, 
and simulation system. These segments provide input information for the input module, modeling module, simulation module, and validation module, respectively, of a digital twin dedicated to administering surface roughness in a human-cyber-physical system.

The semantic annotation segment of the dataset boils down to a concept map. A human- and machine-readable concept map is developed for the dataset of surface roughness. The information of other segments (roughness model, simulation algorithm, and simulation system) can be integrated with the semantic annotation, which is done in this article.

The delay map of surface roughness profile heights plays a pivotal role in the dataset preparation.

It is confirmed that the proposed method can be used to prepare datasets of surface roughness of milling, turning, grinding, electrical discharge machining, and polishing. In the next phase of this study, the surface profile height datasets of other processes will be considered to prepare surface roughness BD comprehensively.

Instead of the surface roughness modeling method used in this study, other modeling methods such as Markov chain, DNA-based computing, non-stationary Gaussian process, and semantic modeling can be used. The roughness model, simulation algorithm, and simulation system segments are in accord with the modeling method. Even though the dataset segments are reconstructed according to the modeling method, the data structure remains the same. Thus, the dataset structure (semantic annotation, roughness model, simulation algorithm, and simulation system) serves as the metadata of the surface roughness.

Author Contributions: Conceptualization, S.F., T.O. and S.U.; methodology, S.F., T.O. and S.U.; software, S.F. and T.O.; validation, S.F., T.O. and S.U.; formal analysis, S.F., T.O. and S.U.; resources, S.U.; data curation, S.F., T.O. and S.U.; writing—original draft preparation, S.F. and S.U.; writingreview and editing, S.F., T.O. and S.U.; visualization, S.F. and T.O.; supervision, S.U. All authors have read and agreed to the published version of the manuscript.

Funding: This research received no external funding.

Institutional Review Board Statement: Not applicable.

Informed Consent Statement: Not applicable.

Data Availability Statement: Not applicable.

Conflicts of Interest: The authors declare no conflict of interest.

\section{References}

1. Schuh, G.; Anderl, R.; Dumitrescu, R.; Krüger, A.; ten Hompel, M. (Eds.) Industrie 4.0 Maturity Index. Managing the Digital Transformation of Companies—Update 2020—Acatech Study. Available online: https:/ / en.acatech.de/publication/industrie-40-maturity-index-update-2020/ (accessed on 20 October 2021).

2. Zhou, J.; Li, P.; Zhou, Y.; Wang, B.; Zang, J.; Meng, L. Toward New-Generation Intelligent Manufacturing. Engineering 2018, 4 , 11-20. [CrossRef]

3. Sisinni, E.; Saifullah, A.; Han, S.; Jennehag, U.; Gidlund, M. Industrial Internet of Things: Challenges, Opportunities, and Directions. IEEE Trans. Ind. Inform. 2018, 14, 4724-4734. [CrossRef]

4. Aheleroff, S.; Xu, X.; Zhong, R.Y.; Lu, Y. Digital Twin as a Service (DTaaS) in Industry 4.0: An Architecture Reference Model. Adv. Eng. Inform. 2020, 47, 101225. [CrossRef]

5. Ullah, A.S. Modeling and simulation of complex manufacturing phenomena using sensor signals from the perspective of Industry 4.0. Adv. Eng. Inform. 2018, 39, 1-13. [CrossRef]

6. Kusiak, A. Smart manufacturing must embrace big data. Nature 2017, 544, 23-25. [CrossRef]

7. Ullah, A.S. What is knowledge in Industry 4.0? Eng. Rep. 2020, 2, e12217. [CrossRef]

8. Wang, X.; Wan, J. Cloud-Edge Collaboration-Based Knowledge Sharing Mechanism for Manufacturing Resources. Appl. Sci. 2021, 11, 3188. [CrossRef]

9. Wuest, T.; Weimer, D.; Irgens, C.; Thoben, K.-D. Machine learning in manufacturing: Advantages, challenges, and applications. Prod. Manuf. Res. 2016, 4, 23-45. [CrossRef]

10. Zhang, Y.; Qian, C.; Lv, J.; Liu, Y. Agent and Cyber-Physical System Based Self-Organizing and Self-Adaptive Intelligent Shopfloor. IEEE Trans. Ind. Inform. 2016, 13, 737-747. [CrossRef]

11. What Is Big Data? Available online: https://www.oracle.com/big-data/what-is-big-data/ (accessed on 20 October 2021). 
12. Big Data Analytics. Available online: https://www.ibm.com/analytics/hadoop/big-data-analytics (accessed on 20 October 2021).

13. ISO TC 213. Available online: http://www.iso.org/iso/home/store/catalogue_tc/catalogue_tc_browse.htm?commid=54924\& published $=$ on (accessed on 30 May 2021).

14. Bui, S.H.; Vorburger, T.V. Surface metrology algorithm testing system. Precis. Eng. 2007, 31, 218-225. [CrossRef]

15. Moktadir, A.; Ali, S.M.; Paul, S.K.; Shukla, N. Barriers to big data analytics in manufacturing supply chains: A case study from Bangladesh. Comput. Ind. Eng. 2019, 128, 1063-1075. [CrossRef]

16. Motohashi, K. Survey of Big Data Use and Innovation in Japanese Manufacturing Firms. RIETI Policy Discussion Paper, 17-P-027. August 2017. Available online: https://www.rieti.go.jp/jp/publications/pdp/17p027.pdf (accessed on 20 October 2021).

17. Kim, Y.G.; Motohashi, K. Use and Sharing of Big Data, Firm Networks and Their Performance. RIETI Policy Discussion Paper, 19-E-016. March 2019. Available online: https:/ /www.rieti.go.jp/jp/publications/dp/19e016.pdf (accessed on 20 October 2021).

18. Syafrudin, M.; Alfian, G.; Fitriyani, N.L.; Rhee, J. Performance Analysis of IoT-Based Sensor, Big Data Processing, and Machine Learning Model for Real-Time Monitoring System in Automotive Manufacturing. Sensors 2018, 18, 2946. [CrossRef]

19. Wiech, M.; Boffelli, A.; Elbe, C.; Carminati, P.; Friedli, T.; Kalchschmidt, M. Implementation of big data analytics and Manufacturing Execution Systems: An empirical analysis in German-speaking countries. Prod. Plan. Control 2020, 1-16. [CrossRef]

20. Escobar, C.A.; McGovern, M.E.; Morales-Menendez, R. Quality 4.0: A review of big data challenges in manufacturing. J. Intell. Manuf. 2021, 32, 2319-2334. [CrossRef]

21. Yu, W.; Dillon, T.; Mostafa, F.; Rahayu, W.; Liu, Y. A Global Manufacturing Big Data Ecosystem for Fault Detection in Predictive Maintenance. IEEE Trans. Ind. Inform. 2019, 16, 183-192. [CrossRef]

22. Faheem, M.; Butt, R.A.; Ali, R.; Raza, B.; Ngadi, A.; Gungor, V.C. CBI4.0: A Cross-layer Approach for Big Data Gathering for Active Monitoring and Maintenance in the Manufacturing Industry 4.0. J. Ind. Inf. Integr. 2021, 24, 100236.

23. O'Donovan, P.; Leahy, K.; Bruton, K.; O'Sullivan, D.T.J. An industrial big data pipeline for data-driven analytics maintenance applications in large-scale smart manufacturing facilities. J. Big Data 2015, 2, 25. [CrossRef]

24. Shah, D.; Wang, J.; He, Q. Feature Engineering in Big Data Analytics for IoT-Enabled Smart Manufacturing-Comparison between Deep Learning and Statistical Learning. Comput. Chem. Eng. 2020, 141, 106970. [CrossRef]

25. Fang, W.; Guo, Y.; Liao, W.; Ramani, K.; Huang, S. Big data driven jobs remaining time prediction in discrete manufacturing system: A deep learning-based approach. Int. J. Prod. Res. 2020, 58, 2751-2766. [CrossRef]

26. Zhang, C.; Wang, Z.; Ding, K.; Chan, F.T.; Ji, W. An energy-aware cyber physical system for energy Big data analysis and recessive production anomalies detection in discrete manufacturing workshops. Int. J. Prod. Res. 2020, 58, 7059-7077. [CrossRef]

27. Ko, Y.-C.; Fujita, H. An evidential analytics for buried information in big data samples: Case study of semiconductor manufacturing. Inf. Sci. 2019, 486, 190-203. [CrossRef]

28. Ullah, A.S.; Fuji, A.; Kubo, A.; Tamaki, J.; Kimura, M. On the Surface Metrology of Bimetallic Components. Mach. Sci. Technol. 2015, 19, 339-359. [CrossRef]

29. Kubo, A.; Teti, R.; Ullah, A.; Iwadate, K.; Segreto, T. Determining Surface Topography of a Dressed Grinding Wheel Using Bio-Inspired DNA-Based Computing. Materials 2021, 14, 1899. [CrossRef]

30. NIST Surface Roughness Database. Available online: http:/ / physics.nist.gov/VSC/jsp/Database.jsp (accessed on 30 May 2021).

31. Li, T.; Blunt, L.A.; Jiang, X.; Zeng, W. An Information Model for Surface Metrology. Procedia CIRP 2013, 10, 251-258. [CrossRef]

32. Farboodi, M.; Mihet, R.; Philippon, T.; Veldkamp, L. Big Data and Firm Dynamics. AEA Pap. Proc. 2019, 109, 38-42. [CrossRef]

33. Ji, W.; Yin, S.; Wang, L. A big data analytics based machining optimisation approach. J. Intell. Manuf. 2019, 30, 1483-1495. [CrossRef]

34. Ren, S.; Zhao, X.; Huang, B.; Wang, Z.; Song, X. A framework for shopfloor material delivery based on real-time manufacturing big data. J. Ambient. Intell. Humaniz. Comput. 2018, 10, 1093-1108. [CrossRef]

35. Oleghe, O. A predictive noise correction methodology for manufacturing process datasets. J. Big Data 2020, 7, 1-27. [CrossRef]

36. LaCasse, P.M.; Otieno, W.; Maturana, F.P. A hierarchical, fuzzy inference approach to data filtration and feature prioritization in the connected manufacturing enterprise. J. Big Data 2018, 5, 45. [CrossRef]

37. Fill, H.-G. SeMFIS: A flexible engineering platform for semantic annotations of conceptual models. Semant. Web 2017, 8, 747-763. [CrossRef]

38. Fill, H.-G. Semantic annotations of enterprise models for supporting the evolution of model-driven organizations. Enterp. Model. Inf. Syst. Archit. 2018, 13, 1-25.

39. Li, X.; Zhuang, P.; Yin, C. A metadata based manufacturing resource ontology modeling in cloud manufacturing systems. $J$. Ambient. Intell. Humaniz. Comput. 2018, 10, 1039-1047. [CrossRef]

40. Antunes, M.; Gomes, D.; Aguiar, R.L. Towards IoT data classification through semantic features. Futur. Gener. Comput. Syst. 2018, 86, 792-798. [CrossRef]

41. Ramos, L. Semantic Web for manufacturing, trends and open issues: Toward a state of the art. Comput. Ind. Eng. 2015, 90, 444-460. [CrossRef]

42. Bader, S.R.; Maleshkova, M. SOLIOT-Decentralized Data Control and Interactions for IoT. Future Internet 2020, 12, 105. [CrossRef]

43. Bader, S.R.; Maleshkova, M.; Lohmann, S. Structuring Reference Architectures for the Industrial Internet of Things. Futur. Internet 2019, 11, 151. [CrossRef] 
44. Bader, S.R.; Grangel-Gonzalez, I.; Nanjappa, P.; Vidal, M.E.; Maleshkova, M. A Knowledge Graph for Industry 4.0. In The Semantic Web. ESWC 2020. Lecture Notes in Computer Science; Harth, A., Kirrane, S., Ngomo, A.-C.N., Paulheim, H., Rula, A., Gentile, A.L., Haase, P., Cochez, M., Eds.; Springer: Cham, Switzerland, 2020; Volume 12123.

45. Paulus, D.; Pomp, A.; Poth, L.; Lipp, J.; Meisen, T. Current and future industry Recommending Semantic Concepts for Improving the Process of Semantic Modeling. In ICEIS 2018. Lecture Notes in Business Information Processing 363; Enterprise Information Systems; Springer: Cham, Switzerland, 2019.

46. Bizer, C.; Heath, T.; Berners-Lee, T. Linked Data-The Story So Far. Int. J. Semant. Web Inf. Syst. 2019, 5, 1-22. [CrossRef]

47. Liang, S.; Stockinger, K.; de Farias, T.M.; Anisimova, M.; Gil, M. Querying knowledge graphs in natural language. J. Big Data 2021, 8, 1-23. [CrossRef] [PubMed]

48. Ullah, A.S.; Arai, N.; Watanabè, M. Concept Map and Internet-aided Manufacturing. Procedia CIRP 2013, 12, 378-383. [CrossRef]

49. Ghosh, A.K.; Ullah, A.S.; Kubo, A.; Akamatsu, T.; D'Addona, D.M. Machining Phenomenon Twin Construction for Industry 4.0: A Case of Surface Roughness. J. Manuf. Mater. Process. 2020, 4, 11. [CrossRef]

50. Ghosh, A.K.; Ullah, A.S.; Teti, R.; Kubo, A. Developing sensor signal-based digital twins for intelligent machine tools. J. Ind. Inf. Integr. 2021, 24, 100242. [CrossRef]

51. Ullah, A.M.M.S.; Shamsuzzaman, M. Fuzzy Monte Carlo Simulation using point-cloud-based probability-possibility transformation. Simulation 2013, 89, 860-875. [CrossRef]

52. Berners-Lee, T.; Hall, W.; Hendler, J.; Shadbolt, N.; Weitzner, D. Creating a Science of the Web. Science 2006, 313, 769-771. [CrossRef]

53. Berners-Lee, T.; Weitzner, D.J.; Hall, W.; O’Hara, K.; Shadbolt, N.; Hendler, J.A. A Framework for Web Science. Found. Trends Web Sci. 2006, 1, 1-130. [CrossRef]

54. Ullah, A.S.; D'Addona, D.M.; Arai, N. DNA based computing for understanding complex shapes. Biosystems 2014, 117, 40-53. [CrossRef]

55. D'Addona, D.M.; Ullah, A.S.; Matarazzo, D. Tool-wear prediction and pattern-recognition using artificial neural network and DNA-based computing. J. Intell. Manuf. 2015, 28, 1285-1301. [CrossRef]

56. Denkena, B.; Dittrich, M.-A.; Stamm, S.; Wichmann, M.; Wilmsmeier, S. Gentelligent processes in biologically inspired manufacturing. CIRP J. Manuf. Sci. Technol. 2020, 32, 1-15. [CrossRef] 